\title{
35 TWENTY YEARS OF APPLYING GROUNDED THEORY IN INFORMATION SYSTEMS: A Coding Method, Useful Theory Generation Method, or an Orthodox Positivist Method of Data Analysis?
}

\author{
Tony Bryant \\ Leeds Metropolitan University \\ Jim Hughes \\ Salford University \\ Michael D. Myers \\ University of Auckland \\ Eileen Trauth \\ The Pennsylvania State University \\ Cathy Urquhart \\ University of Auckland
}

Grounded theory has been gaining ground in Information Systems as a research method in recent years. Grounded theory has been increasingly used and discussed in IS literature spanning the past decade.

This development mirrors the establishment and wide adoption of qualitative research in information systems which has led to a diversity of approaches in qualitative analysis, among them grounded theory.

The panel examines different applications of grounded theory in information systems, and addresses a number of issues that stem from the use of grounded theory in information systems research. 
- How many grounded theory studies in information systems are pure grounded theory studies that generate a whole theory about a phenomenon? Or is grounded theory used in our field as a blanket term for coding data? What is the difference, and does it matter?

- What is the epistemological position implied by using grounded theory? Does the use of grounded theory imply a positivist stance?

- Does it matter that information systems researchers often use grounded theory coding techniques without understanding the 34-year history and genesis of the methodology?

- What are the alternatives to using grounded theory in information systems? Are there other, less complicated and equally effective approaches to coding and analyzing data?

Eileen Trauth, as chair of the session, will introduce the panel and the main issues. This will be followed by a 10 minute presentation by each panelist. Each panelist will raise particular issues engendered by their own experience and use of grounded theory. After the presentations, the chair will summarize the key points of the debate. Then the audience will have an opportunity to discuss these points and others, and engage in a debate about grounded theory that we hope will both be interesting and wide ranging.

Jim Hughes will discuss the intuitive appeal of grounded theory procedures to novice or beginning researchers in qualitative research, and how IS methodologies may usefully be applied to grounded theory.

Eileen Trauth will discuss epistemological implications of different uses of grounded theory, and the epistemological challenges and benefits of coding for pure grounded theory.

Tony Bryant will discuss the need to rescue grounded theory method from some of its key protagonists. His recent work, including an exchange of ideas with Cathy Urquhart, has sought to demonstrate the philosophical inadequacies of many justifications for using the method, based on Charmaz (2000).

Michael Myers will discuss the issue of qualitative data analysis more broadly, by offering some alternatives to grounded theory analysis. 